\title{
Emphysema distribution and annual changes in pulmonary function in male patients with chronic obstructive pulmonary disease
}

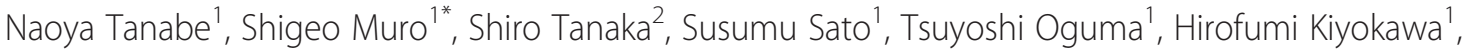 \\ Tamaki Takahashi', Daisuke Kinose' ${ }^{1}$ Yuma Hoshino' ${ }^{1}$,Takeshi Kubo ${ }^{3}$, Emiko Ogawa' ${ }^{1}$, Toyohiro Hirai ${ }^{1}$ \\ and Michiaki Mishima ${ }^{1}$
}

\begin{abstract}
Background: The progression of chronic obstructive pulmonary disease (COPD) considerably varies among patients. Those with emphysema identified by quantitative computed tomography $(\mathrm{CT})$ are associated with the rapid progression assessed by forced expiratory volume in one second $\left(\mathrm{FEV}_{1}\right)$. However, whether the rate of the decline in lung function is independently affected by the regional distribution or the severity of emphysema in the whole lung is unclear.

Methods: We followed up 131 male patients with COPD for a median of 3.7 years. We measured wall area percent (WA\%) in right apical segmental bronchus, total lung volume, percent low attenuation volume (LAV\%), and the standard deviation (SD) of LAV\% values from CT images of 10 isovolumetric partitions (SD-LAV) as an index of cranial-caudal emphysema heterogeneity. Annual changes in $\mathrm{FEV}_{1}$ were then determined using a random coefficient model and relative contribution of baseline clinical parameters, pulmonary function, and CT indexes including LAV\%, SD-LAV, and WA\% to annual changes in $\mathrm{FEV}_{1}$ were examined.

Results: The mean (SD) annual change in FEV was -44.4 (10.8) $\mathrm{mL}$. Multivariate random coefficient model showed that higher baseline $\mathrm{FEV}_{1}$, higher LAV\%, current smoking, and lower SD-LAV independently contributed to an excessive decline in $\mathrm{FEV}_{1}$, whereas ratio of residual volume to total lung capacity, ratio of diffusing capacity to alveolar ventilation, and WA\% did not, after adjusting for age, height, weight, and ratio of CT-measured total lung volume to physiologically-measured total lung capacity.

Conclusions: A more homogeneous distribution of emphysema contributed to an accelerated decline in FEV independently of baseline pulmonary function, whole-lung emphysema severity, and smoking status. In addition to whole-lung analysis of emphysema, CT assessment of the cranial-caudal distribution of emphysema might be useful for predicting rapid, progressive disease and for developing a targeted strategy with which to prevent disease progression.
\end{abstract}

Keywords: Chronic obstructive pulmonary diseases, COPD, CT, Emphysema, Lung function, Heterogeneity

\footnotetext{
* Correspondence: smuro@kuhp.kyoto-u.ac.jp

${ }^{1}$ Department of Respiratory Medicine, Graduate School of Medicine, Kyoto

University, 53 Kawahara-cho, Shogoin, Sakyo-ku, Kyoto 606-8507, Japan

Full list of author information is available at the end of the article
} 


\section{Background}

Chronic obstructive pulmonary disease (COPD) is a leading cause of death that is characterized by airflow limitation [1]. Forced expiratory volume in one second $\left(\mathrm{FEV}_{1}\right)$ is central to assess airflow limitations and diagnose COPD, and the decline in $\mathrm{FEV}_{1}$ is one of the most important outcome measures for evaluating disease progression in longitudinal observational studies and clinical trials [2-5]. On the other hand, the clinical manifestation of COPD is rather heterogeneous in terms of imaging and disease progression [6,7]. Changes in $\mathrm{FEV}_{1}$ might also vary among patients $[4,7,8]$.

Identifying subgroups with different prognostic or therapeutic characteristics as a specific phenotype is important to improve COPD management [6]. Several reports have shown that quantitative computed tomography $(\mathrm{CT})$ is useful for phenotyping patients with COPD because it provides structural information about emphysematous change, airway dimensions and lung volume [9-11]. Especially, since emphysema and airway disease are two major features of COPD and the relative involvement of these two factors considerably vary among patients with COPD, the utility of CT-based categorization (emphysema-predominant, airway-predominant, or mixed) is being increasingly recognized [12-15]. Indeed, it has been shown that CT findings of emphysema, but not airway wall thickening correlate with low body mass index [13], and that both CT measures of emphysema and airway disease are associated with respiratory symptoms and frequency of COPD exacerbations $[14,16]$. We previously demonstrated that the extent of emphysema assessed by CT predicts mortality in patients with COPD independently of $\mathrm{FEV}_{1}$ [17]. Moreover, the decline in $\mathrm{FEV}_{1}$ is greater in patients with, than without the emphysema phenotype [4] and emphysema severity is associated with a rapid annual decline in $\mathrm{FEV}_{1}$ [8]. These findings indicate that the CTbased emphysema phenotype provides information when monitoring patients with COPD.

In addition to the whole lung quantitation of emphysema, CT imaging can quantify the distribution of emphysematous change [18-20]. Quantitative CT studies have shown that the rates of homogeneous emphysema distribution and of lower lung-predominant emphysema in patients with COPD are not as small as estimated from visual assessment [20,21]. Upper lung-dominant emphysema is associated with genetic variants in MMP9 [22] or EPHX1 and GSTP1 [23] and the cranial-caudal emphysema distribution is a powerful predictor of the response to lung volume reduction surgery [24]. Moreover, lower lung-dominant emphysema can predict mortality in patients with emphysema independently of emphysematous changes in the whole lung [25]. These findings suggest that the cranial-caudal heterogeneity of emphysema can be used to further categorize patients with the emphysema phenotype. However, whether regional emphysema heterogeneity affects the rate of disease progression remains unclear.

The present study investigates whether the cranialcaudal heterogeneity of emphysema affects the decline in $\mathrm{FEV}_{1}$ independently of the total amount of emphysematous change. We followed up 131 male patients with COPD for a median period of 3.7 years, and annual changes in $\mathrm{FEV}_{1}$ were calculated using a random coefficient model. We then investigated which factors at study entry can contribute to the decline in $\mathrm{FEV}_{1}$.

\section{Methods}

\section{Study design and study population}

The protocol of this investigation, which was part of an ongoing COPD observational study at Kyoto University, is summarized in Figure 1. Some patients had also participated in our previous studies [10,26,27]. We recruited 163 patients with stable COPD between March 2006 and August 2008 from an outpatient clinic at Kyoto University Hospital. Exclusion criteria comprised a history of chest disease other than COPD, refusal to undergo CT scanning or a diagnosis of $\alpha 1$-antitrypsin deficiency. We excluded 18 patients with abnormal shadows not associated with emphysematous changes in chest CT images at study entry. We also excluded female patients because the number of female patients $(n=9)$ was too small to determine the impact of sex on pulmonary function decline. Thus, 136 male patients who were examined by spirometry every six months were followed up until July 2011. The rate of decline in lung function was analyzed in a dataset of patients in whom $\mathrm{FEV}_{1}$ was measured at least twice as described below. The ethics committee of Kyoto University approved the study (approval No. E182) and all patients provided written informed consent to participate.

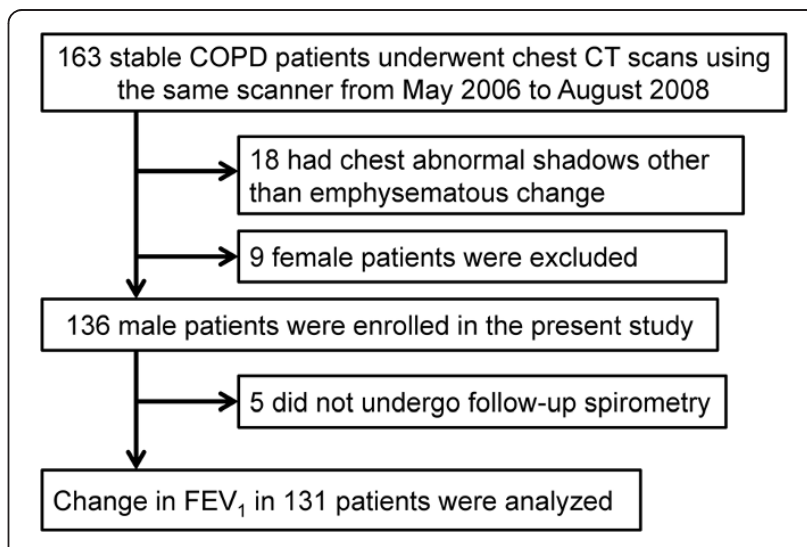

Figure 1 Protocol of the present study. 


\section{Clinical and pulmonary function examinations}

During exacerbation-free periods, the patients inhaled short-acting bronchodilators and then underwent pulmonary function tests (Chestac-65 V; Chest MI Corp; Tokyo, Japan) and high resolution CT at full inspiration (Aquilion 64; Toshiba; Tokyo, Japan; 0.5-mm slice thickness) as described $[10,28]$. Lung volumes and diffusion capacity were measured by helium dilution and the single-breath method, respectively. The use of only one CT scanner avoided inter-scanner variability, and CT parameters were analysed using a custom-designed application [10]. We defined exacerbation of COPD as symptomatic deterioration requiring antibiotics and/or systemic corticosteroid. In patients who had been followed up at Kyoto University Hospital during the year before study entry, exacerbations were counted.

\section{Analysis of $\mathrm{CT}$ images}

We measured total lung volume, the ratio of low attenuation volume to the lung volume (LAV\%) in the whole lung with $-960 \mathrm{HU}$ as the cut-off level, and wall area percent (WA\%) in the right apical segmental bronchus as described $[9,10,28,29]$. By modifying the reported method [16,30], we estimated the level of inspiration during $\mathrm{CT}$ scanning. The ratio of CT-derived total lung volume to physiologically-measured total lung capacity (TLC) was calculated as a proxy for inspiration level, and the proxy was used for statistical analysis. Total lung volume was divided into equal upper and lower regions, and the difference in LAV\% between the two regions was calculated as described $[18,25]$. Positive and negative values for differences represent the upper and lower dominance of emphysema, respectively.

To assess the cranial-caudal heterogeneity of emphysema, we calculated standard deviation (SD) of values of LAV\% in 10 partitions with equal volume (SD-LAV) using a modification of the reported method [19] as follows. As shown in Figure 2, each lung was divided into 12 equal volumes from the top to the base, and the most apical and basal partitions were excluded to eliminate the volume partial effect. Low attenuation volume was measured in each partition. After summing low attenuation volumes of identical partitions in the right and left lungs, LAV\% in each partition was measured by dividing the summed value by the volume of the partition. Then, the SD of LAV $\%$ values in the 10 partitions was calculated to obtain SDLAV. Higher and lower SD-LAV represent the more heterogeneous and homogeneous distribution of emphysema, respectively.

\section{Statistical analyses}

Data are expressed as means \pm SD. Individual annual changes in $\mathrm{FEV}_{1}$ were determined from empirical
Bayes estimates using a random coefficient model with a linear term of time and random effects of intercepts and slopes for each patient. We assessed the relative contributions of $\mathrm{LAV} \%$ and SD-LAV to the annual decline in $\mathrm{FEV}_{1}$ using a random coefficient model that included baseline age, height, weight, percent predicted $\mathrm{FEV}_{1}\left(\% \mathrm{FEV} \mathrm{V}_{1}\right)$, ratio of residual volume to TLC (RV/TLC), ratio of diffusing capacity to alveolar ventilation $\left(\mathrm{D}_{\mathrm{LCO}} / \mathrm{V}_{\mathrm{A}}\right)$, smoking status, LAV\%, SD-LAV, WA\%, and the proxy for inspiration, and the interaction of each covariate with time. A history of frequent exacerbations ( $\geq 2$ exacerbations per year) was not included in the analysis of all the enrolled patients, because 12 of them had not been followed up in the previous year, and they were included only in a supplementary analysis. All $p$-values are two-sided and $p<0.05$ was considered significant. All data were statistically analysed using JMP 7 software (SAS Institute, Cary, NC, USA).

\section{Results}

\section{Characteristics of patients}

Figure 1 shows that we excluded 5 of the 136 enrolled patients without follow-up spirometry. The median follow-up period was 3.7 years, and detailed information about follow-up spirometry, the follow-up period, use of regular COPD medication and clinical course are provided in Supplementary Table E1, E2, and E3 (Additional file 1). We found that of 119 (91\%) patients whose history of exacerbations was recorded for one year before study entry, 15 had experienced at least two exacerbations.

The baseline characteristics of patients and CT parameters are shown in Table 1. SD-LAV\% significantly correlated with the absolute value of the difference in LAV\% between the upper and lower lung regions $(\mathrm{r}=0.94, p<0.001)$, indicating that a higher SD-LAV\% was associated with more upper or lower predominant emphysema.

\section{Annual change in $\mathrm{FEV}_{1}$ and baseline quantitative CT measurements}

The mean (SD) annual change in $\mathrm{FEV}_{1}$ was -44.4 (10.8) $\mathrm{mL}$ (Figure 3). The multivariate random coefficient model showed that a higher $\% \mathrm{FEV}_{1}$, current smoking, higher LAV\% in the whole lung, and lower SD-LAV independently contributed to the annual decline in $\mathrm{FEV}_{1}$, whereas RV/TLC, $\mathrm{D}_{\mathrm{LCO}} / \mathrm{V}_{\mathrm{A}}$, and WA\% did not, after adjustment for age, height, weight, and the proxy for inspiration (Table 2). The findings of this analysis revealed that a $1 \%$ increase in each of $\% \mathrm{FEV}_{1}$ and $\mathrm{LAV} \%$, and a $1 \%$ decrease in SD-LAV contributed to an additional decline of $0.97,2.46$, and $3.24 \mathrm{~mL}$, respectively. The annual decline in $\mathrm{FEV}_{1}$ was $20.90 \mathrm{~mL}$ greater in current, than in former smokers. Our analysis of 119 (91\%) patients 

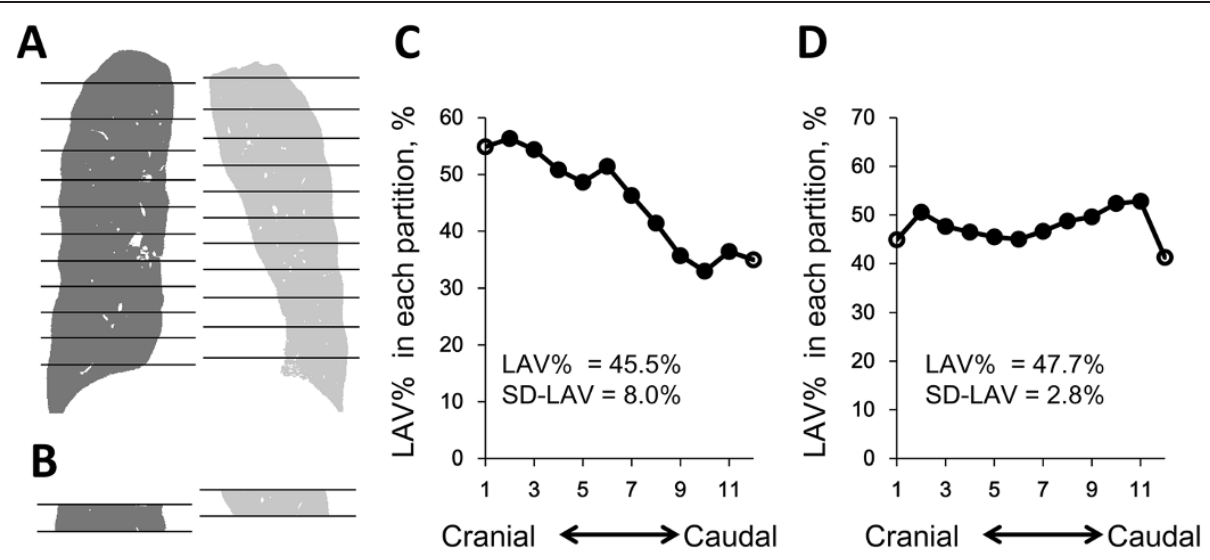

Figure 2 Illustration of the methods to evaluate the cranial-caudal heterogeneity of emphysematous change. Each lung was divided into 12 partitions with equal volumes (A), and LAV\% values in 12 partitions were calculated (B). The top and basal partitions (open circles in $\mathbf{C}$ and $\mathbf{D}$ ) were excluded to avoid volume partial effects. SD-LAV was defined as the standard deviation of LAV\% values in the remaining 10 partitions. C and D showed examples of heterogeneous and homogeneous emphysema, respectively. While LAV\% in C and D were almost similar (45.5 and $47.7 \%$, respectively), SD-LAV in C was higher than in D (8.0 versus $2.8 \%$ ).

showed that SD-LAV remained independently associated with changes in $\mathrm{FEV}_{1}$, whereas a history of frequent exacerbations did not (Table 3).

Table 1 Baseline characteristics of study patients $(n=131)$

\begin{tabular}{|c|c|}
\hline Age (y) & $70.7 \pm 8.8$ \\
\hline Height (cm) & $164.4 \pm 6.1$ \\
\hline Weight (kg) & $58.1 \pm 8.9$ \\
\hline Smoking status (current: former) & $34: 97$ \\
\hline Smoking history (pack-years) & $67.7 \pm 34.1$ \\
\hline \multicolumn{2}{|l|}{ Pulmonary function } \\
\hline $\mathrm{FEV}_{1}(\mathrm{~L})$ & $1.63 \pm 0.68$ \\
\hline$\% \mathrm{FEV}_{1}(\%)$ & $57.9 \pm 19.8$ \\
\hline RV/TLC (\%) & $43.3 \pm 8.1$ \\
\hline $\mathrm{D}_{\mathrm{LCO}} \mathrm{N}_{\mathrm{A}}(\mathrm{mL} / \mathrm{min} / \mathrm{mmHg} / \mathrm{L})$ & $2.77 \pm 1.08$ \\
\hline \multicolumn{2}{|l|}{ CT parameters } \\
\hline LAV\% (\%) & $33.0 \pm 8.6$ \\
\hline Total lung volume $(\mathrm{L})$ & $5.38 \pm 0.9$ \\
\hline Proxy for inspiration & $0.93 \pm 0.13$ \\
\hline WA (right apical bronchus \%) & $57.8 \pm 5.8$ \\
\hline SD-LAV (\%) & $4.1 \pm 2.5$ \\
\hline \multicolumn{2}{|c|}{ Difference in LAV\% (upper - lower lung) } \\
\hline$\geq 0 \%$ (upper predominant) & $n=94$ \\
\hline$<0 \%$ (lower predominant) & $n=37$ \\
\hline
\end{tabular}

Data are expressed as means \pm SD.

Abbreviations: $\mathrm{FEV}_{1}$, forced expiratory volume in one second;

$\% \mathrm{FEV}_{1}, \mathrm{FEV}_{1} \%$ predicted; RV/TLC, ratio of residual volume to total lung capacity;

$\mathrm{D}_{\mathrm{LCO}} / N_{\mathrm{A}}$, ratio of diffusing capacity to alveolar ventilation; LAV\%, ratio of low attenuation volume to total lung volume; WA\%, wall area percent in right apical bronchus:

Proxy for inspiration was defined as the ratio of CT-derived total lung volume to physiologically measured total lung capacity;

SD-LAV, standard deviation of LAV\% values in 10 partitions with equal volumes.

\section{Discussion}

The present study found that in addition to LAV\%, smoking status, and baseline $\% \mathrm{FEV}_{1}$, cranial-caudal emphysema heterogeneity (assessed by SD-LAV) were independently associated with an annual decline in lung function in male patients with COPD. The CTbased emphysema phenotype is associated with a rapid decline in $\mathrm{FEV}_{1}$ and the severity of emphysema increases the risk for a rapid decline [4,8]. However, as far as we can ascertain, this is the first study to prospectively demonstrate that a more homogeneous distribution of emphysema contributes to an accelerated decline in $\mathrm{FEV}_{1}$ independently of the severity of emphysema.

The progression of COPD is heterogeneous [4,6-8]. Exploring risk factors for disease progression and establishing the appropriate phenotype are important to design a targeted strategy for preventing disease progression. Radiographic phenotyping by CT has

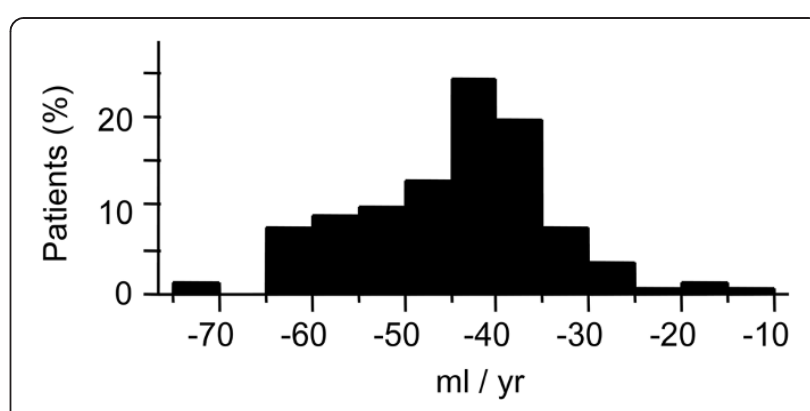

Figure $3 \mathrm{~A}$ histogram of annual change in post-bronchodilator FEV $_{1}$. 
observational studies found a relatively modest decline of 32 to $33 \mathrm{~mL}$ per year $[4,8]$. Some COPD medications such as tiotropium and salmeterol/fluticasone combination might reduce the decline in $\mathrm{FEV}_{1}$ [33,34], and the present study reconfirmed that the baseline severity of airflow limitation is inversely related to the decline in $\operatorname{FEV}_{1} \cdot[4,7,33]$ We speculated that a difference in the baseline characteristics could account for small discrepancies among different studies.

The present study reconfirmed the deleterious effect of smoking and the importance of smoking cessation. Current smoking caused an additional $20.9 \mathrm{~mL}$ per year decline in $\mathrm{FEV}_{1}$ (Table 2). This is consistent with findings of other studies [4,35], in which the rate of decline was $20-30 \mathrm{~mL}$ per year greater in current, than in former smokers.

Exacerbation of COPD can cause a rapid decline in $\mathrm{FEV}_{1}[4,33,36,37]$. We therefore performed a subanalysis (Table 3), which included a history of frequent exacerbations that can identify patients with exacerbation susceptibility [38]. We found that SDLAV remained independently associated with a decline in $\mathrm{FEV}_{1}$. However, the impact of a history of frequent exacerbations was not detected. It have been shown that exacerbations during follow-up are associated with an additional decline in $\mathrm{FEV}_{1}$, but the number of exacerbations in the previous year cannot predict the future decline in $\mathrm{FEV}_{1}[4,33]$. Thus, to further clarify the relative contribution of the emphysema distribution and exacerbations to the decline in $\mathrm{FEV}_{1}$, a model including exacerbations during follow-up should be analyzed in future studies.

$\mathrm{D}_{\mathrm{LCO}} / \mathrm{V}_{\mathrm{A}}$ and RV/TLC were also included in the present random coefficient models. Tables 2 and 3 show that baseline $\mathrm{D}_{\mathrm{LCO}} / \mathrm{V}_{\mathrm{A}}$ and RV/TLC were not associated with the subsequent change in $\mathrm{FEV}_{1}$. The lack of the association of $\mathrm{D}_{\mathrm{LCO}} / \mathrm{V}_{\mathrm{A}}$ with the decline in $\mathrm{FEV}_{1}$ in the model including LAV\% might have been because $D_{\mathrm{LCO}} / \mathrm{V}_{\mathrm{A}}$ correlates well with LAV\%. Indeed, when we constructed the other random coefficient model including the same valuables except $\mathrm{LAV} \%$, lower $\mathrm{D}_{\mathrm{LCO}} / \mathrm{V}_{\mathrm{A}}$ tended to contribute to the decline in $\mathrm{FEV}_{1}(\mathrm{p}=0.051)$.

Since inappropriate inspiration during CT scanning can affect lung density, CT-derived total lung volume has been used to adjust for the variability of the inspiration level [16,39]. Previous studies have estimated the inspiration level by assessing the ratio of CT-derived total lung to predicted TLC $[16,30]$. We modified this method in the present study. The ratio of CT-derived total lung volume to TLC obtained by lung function tests was calculated as the proxy for inspiration level, and then the proxy was included into the multivariate random coefficient model to lessen this confounding effect.
As shown in Supplementary Table E1 (Additional file 1), the present random coefficient model included 14 (11\%) patients whose follow-up periods were less than 2 years. Although patients who were lost to follow-up can be generally included into the random coefficient model, we perform subanalysis of 117 patients who were followed up for at least two years. Consequently, we confirmed that SD-LAV remained independently associated with annual decline in $\operatorname{FEV}_{1}(p=0.009)$.

The limitations in the present study include a smaller study population than those found in other studies [3-5]. However, we used the same scanner to increase consistency among CT data and thus overcome the disadvantages of a small sample cohort. This strategy generated valid information about the severity of emphysema and the heterogeneity of cranial-caudal emphysema.

We could not recruit enough female patients to explore the influence of sex on the decline in $\mathrm{FEV}_{1}$, and thus excluded female patients in the present study. Since susceptibility to cigarette smoke, the severity and distribution of emphysema, and the extent of airway lesions could differ between male and female patients [30,40,41], the present findings cannot be generalized to female patients with COPD.

The present study is observational, and COPD medications were selected by pulmonologists at Kyoto University according to the GOLD guideline [1]. Some COPD medications such as salmeterol/fluticasone combination and tiotropium might have modified the rate of change in $\mathrm{FEV}_{1}[33,34]$. However, we believe that this influence is quite small because the relative contribution of LAV\% and SD-LAV to the change in $\mathrm{FEV}_{1}$ persisted after adjustment for baseline $\% \mathrm{FEV}_{1}$ and a history of exacerbations, which could mainly affect the choice of COPD medication.

We measured airway dimensions in the proximal, but not in the distal airways, although the major site of airway obstruction in patients with COPD is small airways [42]. Since proximal airway dimensions assessed by CT predict histological measurements of small-airway wall dimensions [43], we believe that the location of the airways in which we measured WA\% impacted the present results minimally or not at all.

\section{Conclusion}

We found that a more homogeneous distribution of emphysema independently contributed to an accelerated decline in lung function in addition to higher baseline lung function, more severe emphysematous changes in the whole lung, and current smoking. This not only strengthens the value of the CT-based emphysema phenotype as a predictor of a rapid decline in lung function, but also provides new information; a more homogeneous distribution of emphysema increases susceptibility to rapid disease progression. 


\section{Additional file}

Additional file 1: Supplementary tables for the present study. The number of follow-up spirometry and follow-up period, regular COPD medication during follow-up, and clinical course of study patients are shown in supplementary table E1, E2, and E3, respectively.

\section{Abbreviations}

COPD: Chronic obstructive pulmonary disease; CT: Computed tomography; $\mathrm{D}_{\mathrm{LCO}} N_{\mathrm{A}}$ : Ratio of diffusing capacity to alveolar ventilation; $\mathrm{FEV}_{1}$ : Forced expiratory volume in one second; \%FEV ${ }_{1}$ : Percent predicted $\mathrm{FEV}_{1}$; LAV $\%$ : Percent low attenuation volume; Proxy for inspiration: Ratio of CT-derived total lung volume to physiologically-measured total lung capacity; SDLAV: Standard deviation of values of LAV\% in 10 partitions with equal volume (index for cranial-caudal heterogeneity of emphysema); TLC: Total lung capacity; RV/TLC: Ratio of residual volume to total lung capacity; WA\%: Wall area percent.

\section{Competing interests}

The authors have no conflicts of interest to disclose.

\section{Acknowledgements}

This study was supported by Grants-in-Aid for scientific research (B) (No. 16390234) and (C) (No. 21590964) and a grant to the Respiratory Failure Research Group from the Ministry of Health, Labour and Welfare, Japan. We thank Koji Koizumi and Ryuzo Tanaka for their technical assistance.

\section{Authors' contributions}

NT, SM, ST, SS, TO, HK, TT, DK, YH, TK, EO, TH, and MM contributed to the study design, collection of data, and analysis and interpretation of data. NT and TO contributed to the development of the custom-made application for analyzing $C T$ images. SM and MM contributed to the acquisition of funding. ST contributed to the statistical analysis of data. NT and SM conducted manuscript preparation. All authors have read and approved the final manuscript.

\section{Author details}

'Department of Respiratory Medicine, Graduate School of Medicine, Kyoto University, 53 Kawahara-cho, Shogoin, Sakyo-ku, Kyoto 606-8507, Japan. ${ }^{2}$ Division of Clinical Trial Design and Management, Translational Research Center, Kyoto University Hospital, Kyoto, Japan. ${ }^{3}$ Department of Diagnostic Imaging and Nuclear Medicine, Kyoto University, Kyoto, Japan.

Received: 25 January 2012 Accepted: 18 April 2012

Published: 18 April 2012

\section{References}

1. Global Initiative for Chronic Obstructive Lung Disease. Global Strategy for Diagnosis, Management, and Prevention of COPD. UPDATED 2010. http:// www.goldcopd.com (accessed 10 November 2011).

2. Fletcher $\mathrm{C}$, Peto R: The natural history of chronic airflow obstruction. $\mathrm{Br}$ Med J 1977, 1:1645-1648.

3. Tashkin DP, Celli B, Senn S, Burkhart D, Kesten S, Menjoge S, Decramer M: A 4-year trial of tiotropium in chronic obstructive pulmonary disease. $\mathrm{N}$ Engl J Med 2008, 359:1543-1554.

4. Vestbo J, Edwards LD, Scanlon PD, Yates JC, Agusti A, Bakke P, Calverley PM, Celli B, Coxson HO, Crim C, et al: Changes in forced expiratory volume in 1 second over time in COPD. N Engl J Med 2011, 365:1184-1192.

5. Calverley PM, Anderson JA, Celli B, Ferguson GT, Jenkins C, Jones PW, Yates $J C$, Vestbo J: Salmeterol and fluticasone propionate and survival in chronic obstructive pulmonary disease. N Engl J Med 2007, 356:775-789.

6. Han MK, Agusti A, Calverley PM, Celli BR, Criner G, Curtis JL, Fabbri LM, Goldin JG, Jones PW, Macnee W, et al: Chronic obstructive pulmonary disease phenotypes: the future of COPD. Am J Respir Crit Care Med 2010, 182:598-604.

7. Casanova C, de Torres JP, Aguirre-Jaime A, Pinto-Plata V, Marin JM, Cordoba E, Baz R, Cote C, Celli BR: The progression of chronic obstructive pulmonary disease is heterogeneous: the experience of the BODE cohort. Am J Respir Crit Care Med 2011, 184:1015-1021.
8. Nishimura M, Makita H, Nagai K, Konno S, Nasuhara Y, Hasegawa M, Shimizu K, Betsuyaku T, Ito YM, Fuke S, et al: Annual change in pulmonary function and clinical phenotype in chronic obstructive pulmonary disease. Am J Respir Crit Care Med 2012, 185:44-52.

9. Nakano Y, Muro S, Sakai H, Hirai T, Chin K, Tsukino M, Nishimura K, Itoh H, Pare PD, Hogg JC, Mishima M: Computed tomographic measurements of airway dimensions and emphysema in smokers. Correlation with lung function. Am J Respir Crit Care Med 2000, 162:1102-1108.

10. Tanabe N, Muro S, Hirai T, Oguma T, Terada K, Marumo S, Kinose D, Ogawa E, Hoshino Y, Mishima M: Impact of exacerbations on emphysema progression in chronic obstructive pulmonary disease. Am J Respir Crit Care Med 2011, 183:1653-1659.

11. Mishima M, Hirai T, Itoh H, Nakano Y, Sakai H, Muro S, Nishimura K, Oku Y, Chin K, Ohi M, et al: Complexity of terminal airspace geometry assessed by lung computed tomography in normal subjects and patients with chronic obstructive pulmonary disease. Proc Natl Acad Sci USA 1999, 96:8829-8834.

12. Coxson HO: Quantitative computed tomography assessment of airway wall dimensions: current status and potential applications for phenotyping chronic obstructive pulmonary disease. Proc Am Thorac Soc 2008, 5:940-945.

13. Ogawa E, Nakano Y, Ohara T, Muro S, Hirai T, Sato S, Sakai H, Tsukino M, Kinose D, Nishioka $M$, et al: Body mass index in male patients with COPD: correlation with low attenuation areas on CT. Thorax 2009, 64:20-25.

14. Han MK, Kazerooni EA, Lynch DA, Liu LX, Murray S, Curtis JL, Criner GJ, Kim V, Bowler RP, Hanania NA, et al: Chronic obstructive pulmonary disease exacerbations in the COPDGene study: associated radiologic phenotypes. Radiology 2011, 261:274-282.

15. Kim WJ, Silverman EK, Hoffman E, Criner GJ, Mosenifar Z, Sciurba FC, Make BJ, Carey V, Estepar RS, Diaz A, et al: CT metrics of airway disease and emphysema in severe COPD. Chest 2009, 136:396-404.

16. Grydeland TB, Dirksen A, Coxson HO, Eagan TM, Thorsen E, Pillai SG, Sharma S, Eide GE, Gulsvik A, Bakke PS: Quantitative computed tomography measures of emphysema and airway wall thickness are related to respiratory symptoms. Am J Respir Crit Care Med 2010, 181:353-359.

17. Haruna A, Muro S, Nakano Y, Ohara T, Hoshino Y, Ogawa E, Hirai T, Niimi A, Nishimura K, Chin K, Mishima M: CT scan findings of emphysema predict mortality in COPD. Chest 2010, 138:635-640.

18. Washko GR, Hoffman E, Reilly JJ: Radiographic evaluation of the potential lung volume reduction surgery candidate. Proc Am Thorac Soc 2008, 5:421-426.

19. Stolk J, Versteegh MI, Montenij LJ, Bakker ME, Grebski E, Tutic M, Wildermuth S, Weder W, el Bardiji M, Reiber JH, et al: Densitometry for assessment of effect of lung volume reduction surgery for emphysema. Eur Respir J 2007, 29:1138-1143.

20. Cederlund K, Tylen U, Jorfeldt L, Aspelin P: Classification of emphysema in candidates for lung volume reduction surgery: a new objective and surgically oriented model for describing $\mathrm{CT}$ severity and heterogeneity. Chest 2002, 122:590-596.

21. Stavngaard T, Shaker SB, Dirksen A: Quantitative assessment of emphysema distribution in smokers and patients with alpha1-antitrypsin deficiency. Respir Med 2006, 100:94-100.

22. Ito I, Nagai S, Handa T, Muro S, Hirai T, Tsukino M, Mishima M: Matrix metalloproteinase-9 promoter polymorphism associated with upper lung dominant emphysema. Am J Respir Crit Care Med 2005, 172:1378-1382.

23. DeMeo DL, Hersh CP, Hoffman EA, Litonjua AA, Lazarus R, Sparrow D, Benditt JO, Criner G, Make B, Martinez FJ, et al: Genetic determinants of emphysema distribution in the national emphysema treatment trial. Am J Respir Crit Care Med 2007, 176:42-48.

24. Fishman A, Martinez F, Naunheim K, Piantadosi S, Wise R, Ries A, Weinmann $G$, Wood DE: A randomized trial comparing lung-volume-reduction surgery with medical therapy for severe emphysema. N Engl J Med 2003, 348:2059-2073.

25. Martinez FJ, Foster G, Curtis JL, Criner G, Weinmann G, Fishman A, DeCamp MM, Benditt J, Sciurba F, Make B, et al: Predictors of mortality in patients with emphysema and severe airflow obstruction. Am J Respir Crit Care Med 2006, 173:1326-1334.

26. Terada K, Muro S, Sato S, Ohara T, Haruna A, Marumo S, Kinose D, Ogawa E, Hoshino Y, Niimi A, et al: Impact of gastro-oesophageal reflux disease symptoms on COPD exacerbation. Thorax 2008, 63:951-955. 
27. Terada K, Muro S, Ohara T, Kudo M, Ogawa E, Hoshino Y, Hirai T, Niimi A, Chin K, Mishima M: Abnormal swallowing reflex and COPD exacerbations. Chest 2010, 137:326-332.

28. Ohara T, Hirai T, Muro S, Haruna A, Terada K, Kinose D, Marumo S, Ogawa E, Hoshino Y, Niimi A, et al: Relationship between pulmonary emphysema and osteoporosis assessed by CT in patients with COPD. Chest 2008, 134:1244-1249.

29. Ohara T, Hirai T, Sato S, Terada K, Kinose D, Haruna A, Marumo S, Nishioka M, Ogawa E, Nakano Y, et al: Longitudinal study of airway dimensions in chronic obstructive pulmonary disease using computed tomography. Respirology 2008, 13:372-378.

30. Grydeland TB, Dirksen A, Coxson HO, Pillai SG, Sharma S, Eide GE, Gulsvik A, Bakke PS: Quantitative computed tomography: emphysema and airway wall thickness by sex, age and smoking. Eur Respir J 2009, 34:858-865.

31. Bafadhel M, Umar I, Gupta S, Raj JV, Vara DD, Entwisle JJ, Pavord ID, Brightling CE, Siddiqui S: The Role of CT Scanning in Multidimensional Phenotyping of COPD. Chest 2011, 140:634-642.

32. Mair G, Maclay J, Miller JJ, McAllister D, Connell M, Murchison JT, MacNee W: Airway dimensions in COPD: relationships with clinical variables. Respir Med 2010, 104:1683-1690.

33. Celli BR, Thomas NE, Anderson JA, Ferguson GT, Jenkins CR, Jones PW, Vestbo J, Knobil K, Yates JC, Calverley PM: Effect of pharmacotherapy on rate of decline of lung function in chronic obstructive pulmonary disease: results from the TORCH study. Am J Respir Crit Care Med 2008, 178:332-338.

34. Decramer M, Celli B, Kesten S, Lystig T, Mehra S, Tashkin DP: Effect of tiotropium on outcomes in patients with moderate chronic obstructive pulmonary disease (UPLIFT): a prespecified subgroup analysis of a randomised controlled trial. Lancet 2009, 374:1171-1178.

35. Scanlon PD, Connett JE, Waller LA, Altose MD, Bailey WC, Buist AS: Smoking cessation and lung function in mild-to-moderate chronic obstructive pulmonary disease. The Lung Health Study. Am J Respir Crit Care Med 2000, 161:381-390

36. Donaldson GC, Seemungal TA, Bhowmik A, Wedzicha JA: Relationship between exacerbation frequency and lung function decline in chronic obstructive pulmonary disease. Thorax 2002, 57:847-852.

37. Kanner RE, Anthonisen NR, Connett JE: Lower respiratory illnesses promote FEV(1) decline in current smokers but not ex-smokers with mild chronic obstructive pulmonary disease: results from the lung health study. Am J Respir Crit Care Med 2001, 164:358-364.

38. Hurst JR, Vestbo J, Anzueto A, Locantore N, Mullerova $H$, Tal-Singer R, Miller B, Lomas DA, Agusti A, Macnee W, et al: Susceptibility to exacerbation in chronic obstructive pulmonary disease. N Engl J Med 2010, 363:1128-1138.

39. Stoel BC, Putter H, Bakker ME, Dirksen A, Stockley RA, Piitulainen E, Russi EW, Parr D, Shaker SB, Reiber JH, Stolk J: Volume correction in computed tomography densitometry for follow-up studies on pulmonary emphysema. Proc Am Thorac Soc 2008, 5:919-924.

40. Gan WQ, Man SF, Postma DS, Camp P, Sin DD: Female smokers beyond the perimenopausal period are at increased risk of chronic obstructive pulmonary disease: a systematic review and meta-analysis. Respir Res 2006, 7:52

41. Martinez FJ, Curtis JL, Sciurba F, Mumford J, Giardino ND, Weinmann G, Kazerooni E, Murray S, Criner GJ, Sin DD, et al: Sex differences in severe pulmonary emphysema. Am J Respir Crit Care Med 2007, 176:243-252.

42. Hogg JC, Chu F, Utokaparch S, Woods R, Elliott WM, Buzatu L, Cherniack RM, Rogers RM, Sciurba FC, Coxson HO, Pare PD: The nature of small-airway obstruction in chronic obstructive pulmonary disease. N Engl J Med 2004, 350:2645-2653.

43. Nakano Y, Wong JC, de Jong PA, Buzatu L, Nagao T, Coxson HO, Elliott WM, Hogg JC, Pare PD: The prediction of small airway dimensions using computed tomography. Am J Respir Crit Care Med 2005, 171:142-146.

doi:10.1186/1465-9921-13-31

Cite this article as: Tanabe et al:: Emphysema distribution and annual changes in pulmonary function in male patients with chronic obstructive pulmonary disease. Respiratory Research 2012 13:31.

\section{Submit your next manuscript to BioMed Central and take full advantage of:}

- Convenient online submission

- Thorough peer review

- No space constraints or color figure charges

- Immediate publication on acceptance

- Inclusion in PubMed, CAS, Scopus and Google Scholar

- Research which is freely available for redistribution 